\title{
THE EFFECT OF THE USE OF MOBILE TECHNOLOGIES BY MANAGEMENT IN POLISH MANUFACTURING ENTERPRISES ON THE EFFICIENCY OF KNOWLEDGE TRANSFER WITHIN A COMPANY
}

\author{
Justyna PATALAS-MALISZEWSKA
}

University of Zielona Góra, Zielona Góra, Poland

e-mail: J.Patalas@iizp.uz.zgora.pl

\begin{abstract}
This article elaborates an existence of a positive effect of the use of mobile technologies by managers, according to their competences, on the efficiency of explicit knowledge transfer in a manufacturing company. It focuses on the set of the competences of managers, who use the mobile technologies in manufacturing companies and is based on a survey and data obtained from 119 Polish manufacturing enterprises. This article develops a framework of how managers can determinate the knowledge transfer in a manufacturing company and further discusses the research results.
\end{abstract}

Keywords: case study, knowledge management tools, knowledge transfer, inter-organizational.

\section{1}

\section{Introduction}

This research analyzes the use of mobile technology by management in Polish manufacturing companies in order to identify its influence on the efficiency of knowledge transfer among employees in those enterprises. According to Albino et al. [4], the firm management has to be evaluated in terms of interest to develop relationships also within an organization. The use of mobile technologies in manufacturing companies is understood to be able to provide workers with a real-time insight into operational and business activities regardless of their physical location. Additionally, it is assumed that the use of mobile applications, for example, smartphones, can be often integrated into legacy systems in manufacturing companies. Naturally, companies still have problems with how to integrate mobile applications with a pre-established and well-used information system. According to Chituc, Americo and Cesar [5]; many companies are in the process of adapting business concepts from traditional practices to e-businesses. Although changes in the currently-used information systems in manufacturing companies (e.g. MES, ERP) are often needed, it is not an easy task because of the heterogeneity of information resources.

According to Santoro and Saparito [23] and Williams [25], this study focuses on inter-organizational knowledge transfer and tries to explore the role of the use of knowledge-transfer support applications as a mobile technology. Effective knowledge transfer within a company is not easy to achieve the wide variety of business processes. There are strong indications of knowledge transfer among workers for potential collaboration, and generally speaking, information technology (IT) is essentially regarded as a natural medium for managing knowledge [13]. The work of Nonaka and Von Krogh [18] was chosen as the foundation of this research and three objectives were identified to provide direction for this exploratory research. The first objective explores whether managers appropriately exploit the usage of mobile technologies across different processes and whether, as described by Nonaka and Von Krogh, this has a significant influence on knowledge transfer within a company. The second objective was to explore whether the managers' usage of mobile technologies is different for tacit and explicit knowledge transfer. Inter-organizational knowledge includes both explicit knowledge, such as work reports and official documents and tacit knowledge, such as like experience, ideas, and expertise from employees. The third objective explores the efficiency of knowledge transfer and whether the use of mobile technology may have some influence on this.

This study explores the use of knowledge transfer support applications as a mobile technology and as an important construct for understanding what tacit or explicit knowledge may be transferred more effectively in manufacturing companies. 
The remainder of this paper is organized as follows: Section 2 presents the theoretical background of the study. Section 3 describes a conceptual model and the research methodology. Section 4 examines the research results. Section 5 discusses the implications of the results, provides a conclusion and highlights the limitations of this research.

\section{Objectives to be explored}

Added value for a company can be determined among others as an effective investment in knowledge [8, 20, 21, and 22].

Knowledge transfer is adopted from Ko et al. [12] and defined as a process with two sub-processes: sending knowledge and receiving knowledge. Kim et al. [11] defined inter-organizational knowledge transfer as a critical factor for collaborative resource coordination. Moreover, Joshi et al. [10] found empirical evidence to support the positive role that a knowledge source plays in team knowledge transfer.

Generally speaking, knowledge can be classified as either tacit or explicit. Explicit knowledge can be transferred through verbal explanation, documents and/or information systems and tacit knowledge transfer may be achieved through the re-creation of knowledge [16]. According to Nonaka et al. [17]; tacit and explicit knowledge can exist on a continuum. This research explores the following types of explicit interorganizational knowledge in a manufacturing company - policies (EK-P), procedures (EK-PR), and data bases (EK-DB) - and types of tacit inter-organizational knowledge - research excellence (TK-RE), management know-how (TK$\mathrm{KH})$ and organizational culture (TK-OC) [14].

Cotora [6] stated that it is necessary to identify the relationships among competencies and partnerships in a company for the success of a company. This research elaborates the efficiency of knowledge transfer, both explicit and tacit, in a manufacturing company according to the principles of Hausman and Johnston [9] and suggested that we should understand the manifestation of this efficiency as an influence on the number of successful projects that are achieved.
Albino et al [3] defined four elements that have an positive impact on the knowledge transfer: the actors in the knowledge transfer process and the context of this process, the content and the media. In this study are also those items involved understood as: actors are managers with the competences in the polish manufacturing companies, knowledge is transferred across different processes via mobile technologies in a company to improve the number of successful projects within an organization.

So, in this study, the following competencies of managers in manufacturing companies for the success of realized projects are defined $[2,7]$ :

- organizational and management competencies (OMC),

- technical competencies (TC),

- behavioral competences (BC).

The three issues defined for further investigation that follow from this are:

\section{- Objective 1}

Managers in manufacturing companies use mobile technologies across different processes according to their competences and those competences influence the type of knowledge that is transferred.

\section{- Objective 2}

Managers in manufacturing companies use mobile technologies across different processes according to their competences and those competences have a different influence on tacit and explicit knowledge transfer.

\section{- Objective 3}

The use of mobile technologies by managers in manufacturing companies influences the efficiency of knowledge transfer that can be understood via an improvement in the number of successful projects.

This study posits that knowledge (both explicit and tacit) is transferred by the sender(s) to the receiver(s) via the use of mobile technologies by managers across the different processes in a manufacturing company. Managers need to know why and how the knowledge can influence positive on business performance [24]. The conceptual model shown in Fig. 1 depicts the relationships that is examined. 


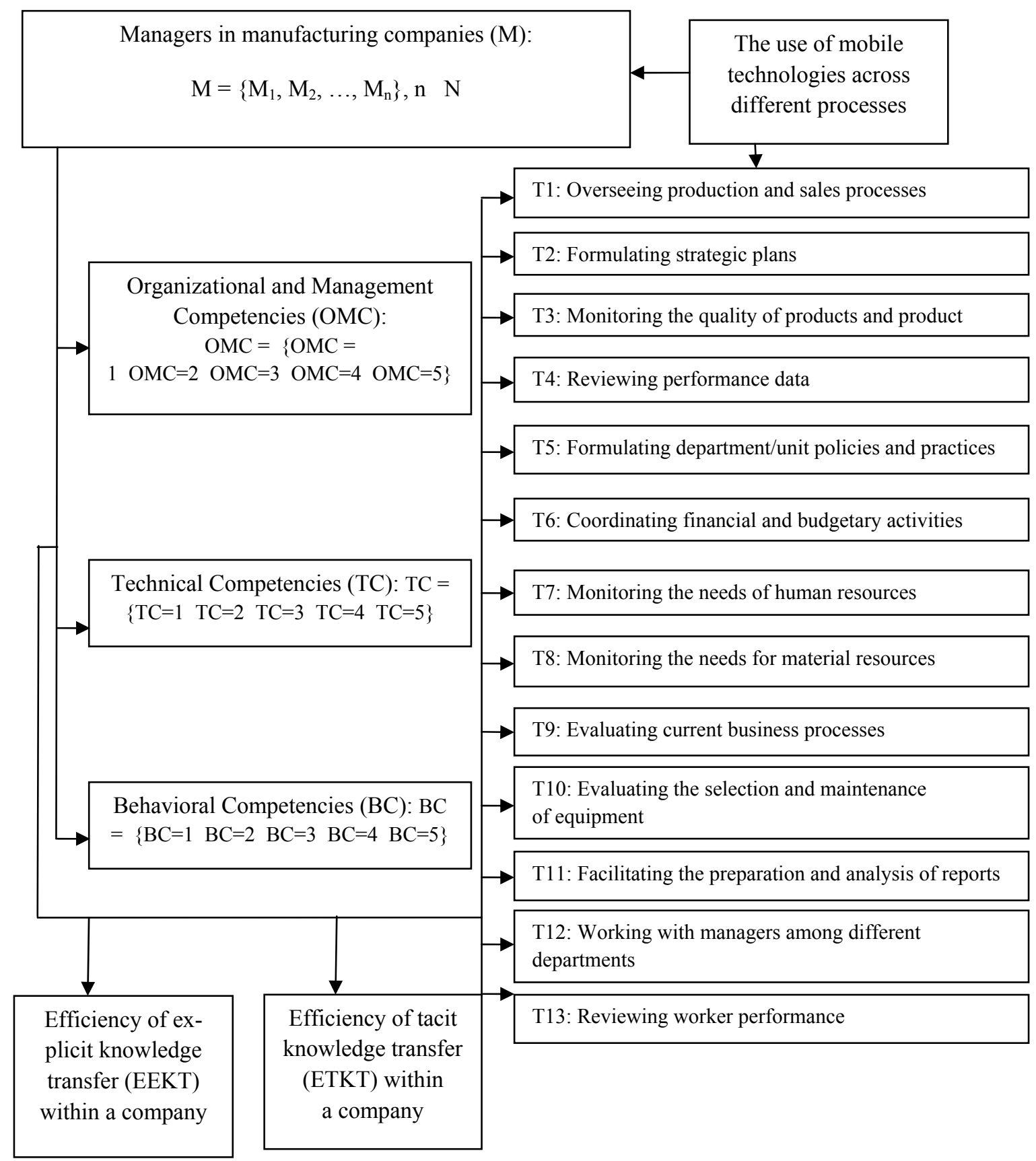

Figure 1. The conceptual model

The conceptual model also incorporated the findings of Park, Vertinsky and Becerra [19], and it is stated that explicit knowledge is knowledge that may be articulated, codified, and stored, whereas tacit knowledge may be acquired mainly through observations and interactions.

The conceptual model also incorporated the findings of Park, Vertinsky and Becerra (2015) [19] and it is stated that explicit knowledge is knowledge that may be articulated, codified, and stored; whereas tacit knowledge may be acquired mainly through observations and interactions.

\section{$3 \quad$ Measures and methods}

The methodology chosen was qualitative research, starting with carrying out surveys in a number of Polish manufacturing companies. Before the study, it was assumed that in those companies that took part in the research, managers would typically realize at least $80 \%$ of the defined activities 
in their manufacturing company (Fig. 1) and that mobile technologies were used to support these processes.

This study expects that managers with a defined level of competence can effectively transform knowledge within Polish manufacturing companies (according to Marra et al. [15] it is stated that knowledge flows from one worker to another) and that using mobile technologies will positively influence the improvement of the number of successful projects.

Factors that describe the competences of managers to transfer knowledge in a Polish manufacturing company were based on the feedback surveys and their sources are listed as follows:

Competence of a manager: The degree of my competence can help to transform knowledge among others:

- C-factor1: I know that in my organization, my competence is completely unimportant for knowledge transfer,

- C-factor2: I know that in my organization, my competence is not important for knowledge transfer,

- C-factor3: I know that in my organization, my competence is marginally important for knowledge transfer,

- C-factor4: I know that in my organization, my competence is important for knowledge transfer,

- C-factor5: I know that in my organization, my competence is very important for knowledge transfer.

Factors of explicit and tacit interorganizational knowledge were based on the feedback surveys and their sources are listed as follows.

Explicit/tacit interorganizational knowledge:

The degree to which the transfer of explicit knowledge - policies (EK-P), procedures (EK-PR), and databases (EK-DB) - and tacit knowledge research excellence (TK-RE), management knowhow (TK-KH), and organizational culture (TK-OC) [14] - within an enterprise improves the number of successful projects.

- Know-factor1: I know that in my organization, explicit/tacit knowledge transfer is completely unimportant for increasing the number of successful projects,

- Know-factor2: I know that in my organization, explicit/tacit knowledge transfer is not important for increasing the number of successful projects,

- Know-factor3: I know that in my organization, explicit/tacit knowledge transfer is quite important for increasing the number of successful projects,

- Know-factor4: I know that in my organization, explicit/tacit knowledge transfer is important for increasing the number of successful projects,

- Know-factor5: I know that in my organization, explicit/tacit knowledge transfer is very important for increasing the number of successful projects.

The surveys used for testing the research model were developed by defining scales to fit the knowledge codification context. A five-point scale was used for all survey items. The data for this study were collected from 119 Polish manufacturing companies between January and September, 2014. The Polish manufacturing companies consisted of various manufacturing types: industry: 88 companies (74\%), construction: 16 companies (13\%), and others: 15 companies $(13 \%)$. The respondents were managers (95 companies, 80\%) and chief executive officers (24 companies, 20\%); hence, the defined objectives can be discussed based on these research results.

\section{$4 \quad$ Research results}

The research model was analyzed using a correlation and further regression approach in order to estimate the effect of the use of mobile technologies by management on the efficiency of knowledge transfer in the studied Polish manufacturing enterprises. A moderated correlation approach, using Statistica ver.10.0, was used to test the defined objectives. The data were carefully examined with respect to linearity, equality of variance and normality. No significant deviations were detected. Table 1 presents descriptive correlations for the main variables. The study tests the hypotheses using a correlation analysis because an interaction effect exists only if the interaction term makes a significant contribution. 
Table 1. The results of the effect of the use of mobile technologies by managers of manufacturing companies, according to their competences, on the efficiency of explicit and tacit knowledge transfer

\begin{tabular}{|c|c|c|c|c|}
\hline $\begin{array}{c}\text { Construct } \\
\text { Item: } \\
\text { C-factor1/C-factor2/C-factor3/C- } \\
\text { factor4/C-factor5 } \\
\text { Know-factor1/ Know-factor2/ Know- } \\
\text { factor3/ Know-factor4/ Know-factor5) }\end{array}$ & Correlation & r2 & $\mathbf{t}$ & p \\
\hline OMC/ EK-P & 0.4387 & 0.1925 & 5.2812 & 0.0000 \\
\hline OMC/ EK-PR & 0.3765 & 0.1418 & 4.3960 & 0.0000 \\
\hline OMC/ EK-DB & 0.1602 & 0.0257 & 1.7555 & 0.0818 \\
\hline TC/ EK-P & 0.3407 & 0.1161 & 3.9200 & 0.0002 \\
\hline TC/ EK-PR & 0.3202 & 0.1025 & 3.6554 & 0.0004 \\
\hline TC/ EK-DB & 0.0820 & 0.0067 & 0.8896 & 0.3755 \\
\hline BC/ EK-P & 0.2640 & 0.0697 & 2.9607 & 0.0037 \\
\hline BC/ EK-PR & 0.3938 & 0.1551 & 4.6338 & 0.0000 \\
\hline BC/ EK-DB & 0.1255 & 0.0157 & 1.3680 & 0.1739 \\
\hline OMC/ TK -RE & -0.0187 & 0.0003 & -0.2019 & 0.8404 \\
\hline OMC/ TK-KH & 0.0612 & 0.0037 & 0.6632 & 0.5085 \\
\hline $\mathrm{OMC} / \mathrm{TK}-\mathrm{OC}$ & 0.1407 & 0.0198 & 1.5373 & 0.1269 \\
\hline TC/ TK -RE & -0.0446 & 0.0020 & -0.4832 & 0.6298 \\
\hline TC/ TK-KH & -0.0631 & 0.0040 & -0.6842 & 0.4952 \\
\hline TC/ TK-OC & 0.0450 & 0.0020 & 0.4868 & 0.6273 \\
\hline $\mathrm{BC} / \mathrm{TK}-\mathrm{RE}$ & -0.0386 & 0.0015 & -0.4174 & 0.6772 \\
\hline BC/ TK-KH & 0.0214 & 0.0005 & 0.2313 & 0.8175 \\
\hline $\mathrm{BC} / \mathrm{TK}-\mathrm{OC}$ & -0.0030 & 0.0000 & -0.0319 & 0.9746 \\
\hline
\end{tabular}

Table 1 includes the results of the correlation analyses which estimate the effect of the use of mobile technologies by managers of manufacturing companies, according to their competences, on the efficiency of explicit and tacit knowledge transfer, understood via an improvement in the number of successful projects.

The interaction of the competences of managers in a manufacturing company makes a significant contribution only to the efficiency of explicit knowledge transfer, such as policies and procedures.

The first objective that was identified from the literature was significant because the managers in the manufacturing companies used mobile technologies across different processes, according to their competences, and those competences had an influence on the explicit knowledge that was transferred.

The second objective was also illustrated because interaction involving the competencies of managers and explicit knowledge transfer is very significant and, unfortunately, this interaction between tacit knowledge transfer is not observed.

Regarding the third objective, the use of mobile technologies by managers in manufacturing companies influences the efficiency of knowledge transfer understood via an improvement in the number of successful projects, but this being true only for explicit knowledge transfer. 
The research results, which are based on a survey and data obtained from 119 managers and chief executive officers of 119 Polish manufacturing enterprises, show that the use of mobile technologies by managers with specific competencies has a positive effect on the efficiency of explicit knowledge transfer in an enterprise. By the use of mobile technologies, managers can transmit reports and statements and have the possibility to make decisions in realtime. Those activities actually influence the implementation of successful projects. To determine the nature of any significant interactions of the compe- tences of managers and any explicit knowledge transfer within a company, the study tests its objectives using regression analyses that are able to estimate this effect.

To determine the nature of the first significant interaction, the organizational and management competence of managers and explicit knowledge transfer (policies) the study plots the effect (see Fig. 2). The efficiency of explicit knowledge transfer (policies) clearly increases when managers use mobile technologies and have organizational and management competences.
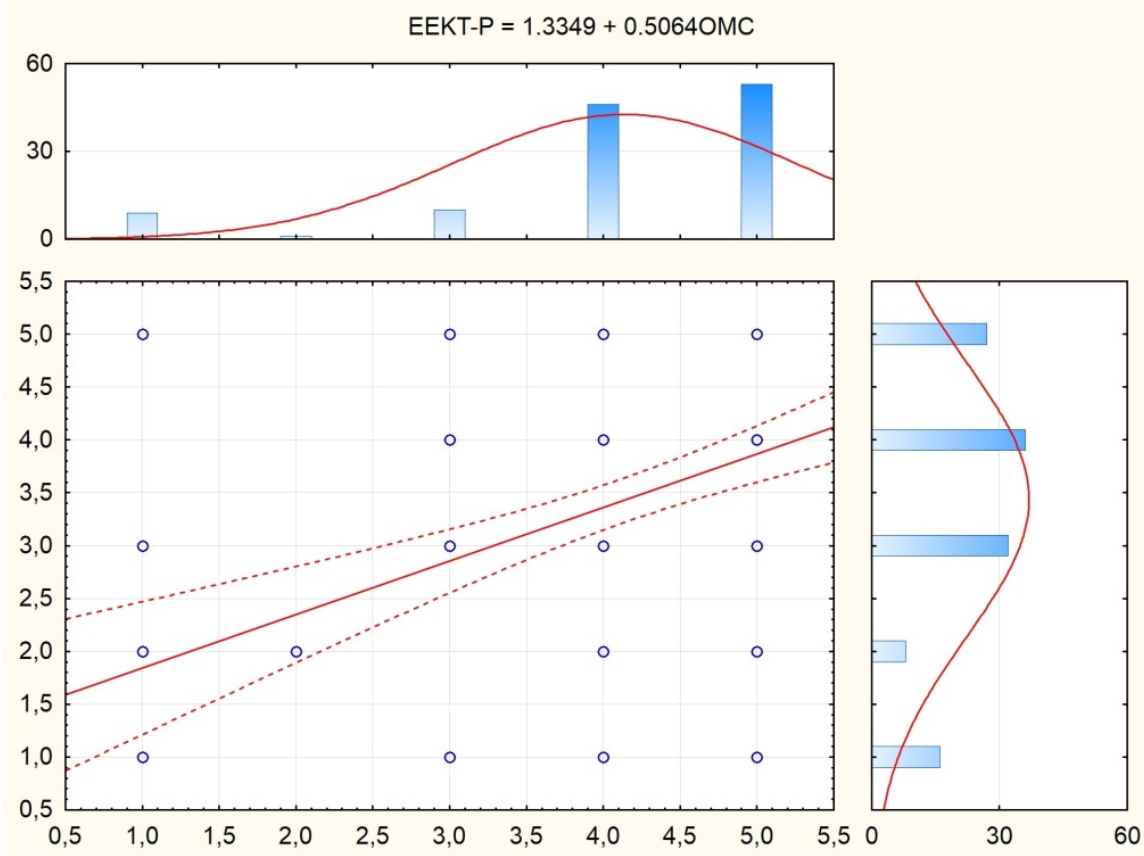

Figure 2. Interactions involving the organizational and management competencies of managers who use mobile technologies and the resulting effects on explicit knowledge transfer (policies)

Fig. 3 indicates that the efficiency of knowledge transfer (procedures) within a company clearly increases when managers use mobile technologies and have organizational and management competences. Fig. 4 and 5 present the effects of the significant contributions of the technical competences of managers in a manufacturing company and the efficiency of policies and procedures transfer.
Moreover, the relationship between the behavioral competences of managers in a manufacturing company who use mobile technologies and the transfer of policies and procedures is also positive (Figs. 6 and 7). 


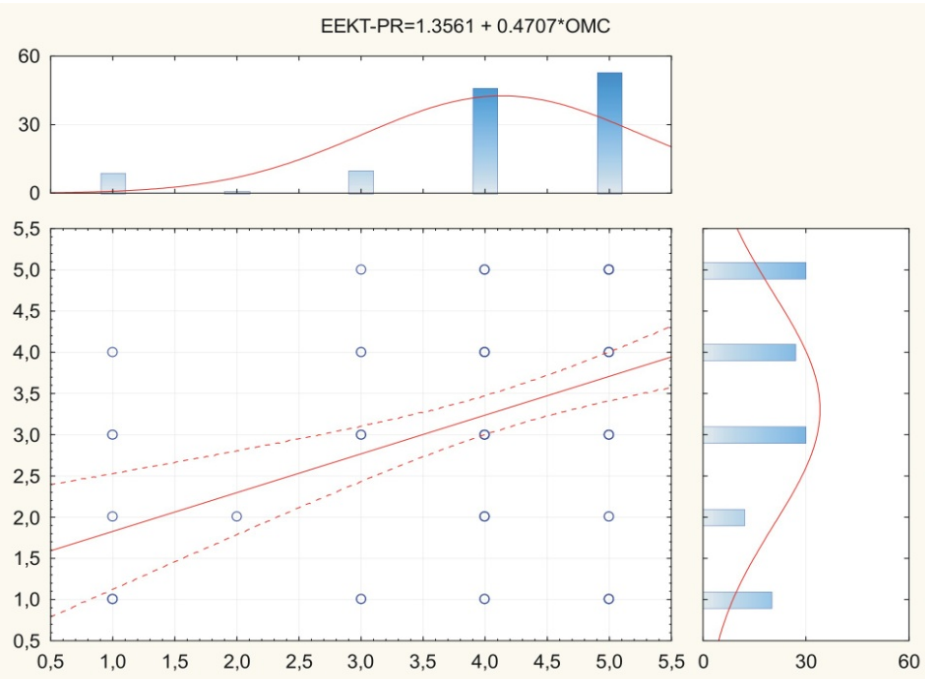

Figure 3. Interactions involving the organizational and management competencies of managers who use mobile technologies and the resulting effects on explicit knowledge transfer (procedures)

EEKT-P $=1.5104+0.4280 * T C$
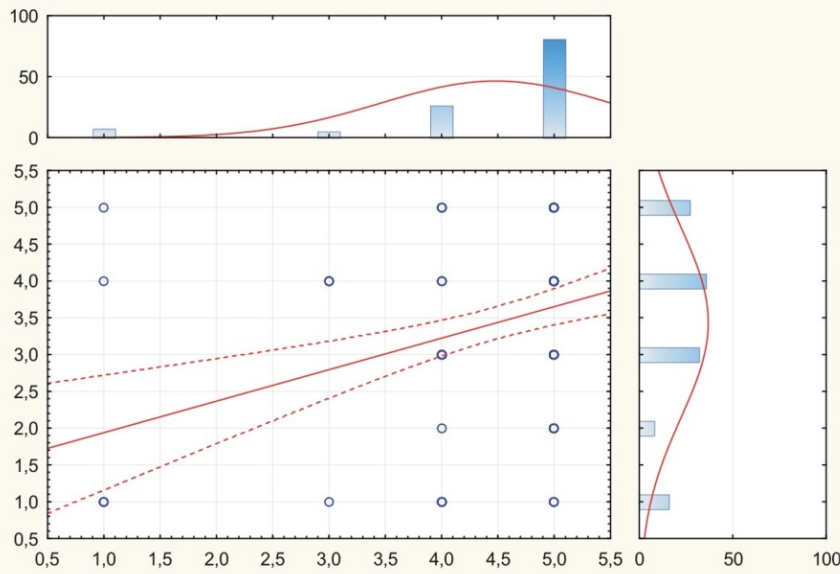

Figure 4. Interactions involving the technical competencies of managers who use mobile technologies and the resulting effects on explicit knowledge transfer (policies)
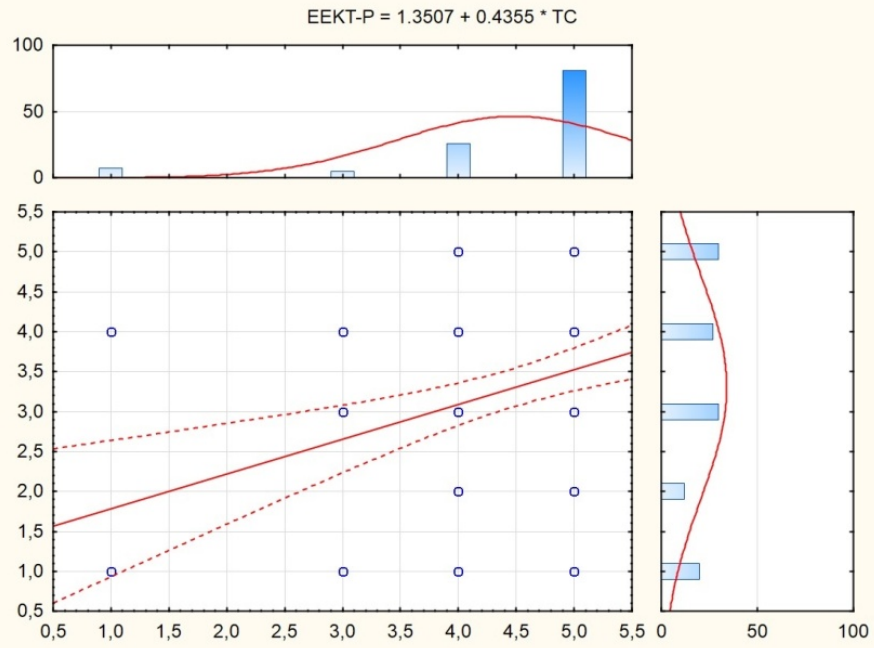

Figure 5. Interactions involving the technical competencies of managers who use mobile technologies and the resulting effects on explicit knowledge transfer (procedures) 


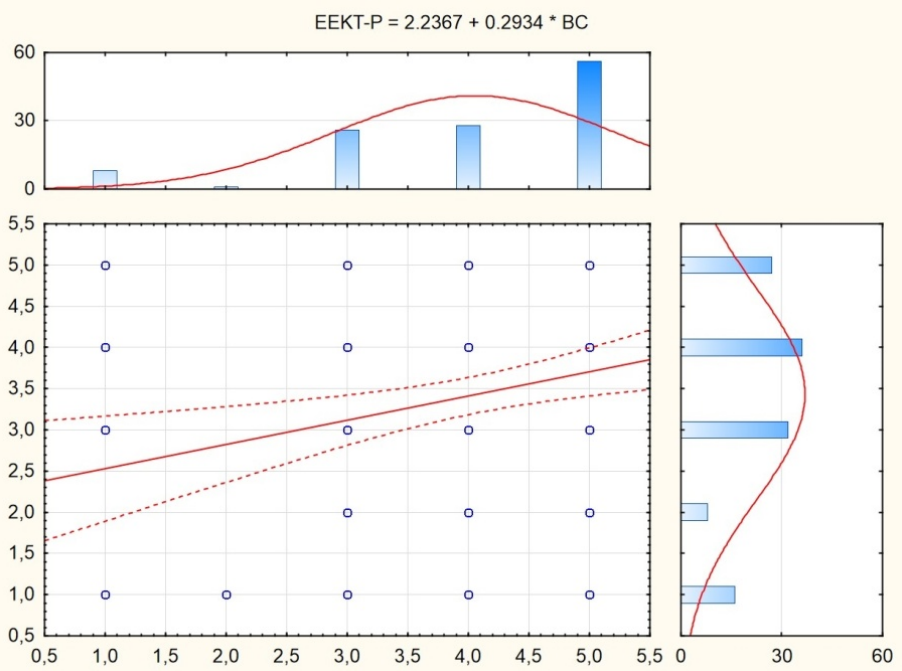

Figure 6. Interactions involving the behavioral competencies of managers who use mobile technologies and the resulting effects on explicit knowledge transfer (policies)
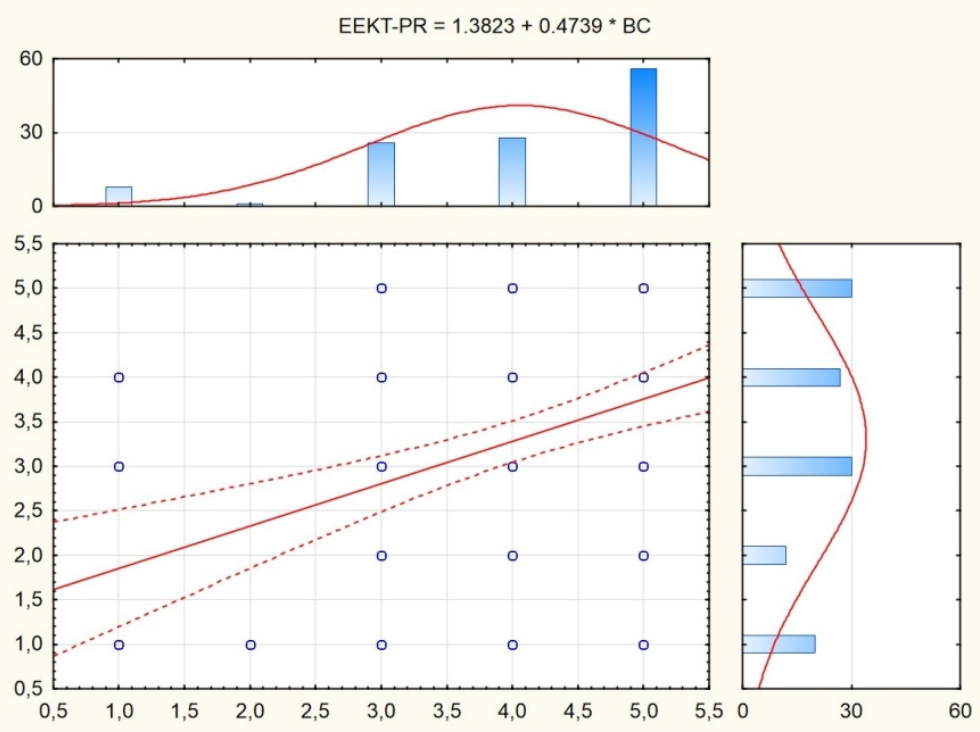

Figure 7. Interactions involving the behavioral competencies of managers who use mobile technologies and the resulting effects on explicit knowledge transfer (procedures)

This study does not only testify to the influence of the use of mobile technologies by managers, according to their competences, on the efficiency of knowledge transfer in a manufacturing company, but also explores how this mechanism works. Therefore, a potential model based on this research for assessing the efficiency of inter-organizational knowledge transfer can be formulated:

The efficiency of explicit knowledge transfer $($ EEKT $)=$ the organizational and management competencies (OMC) of managers in a manufacturing company who use mobile technologies + the technical competencies (TC) of managers in a manufac- turing company who use mobile technologies + the behavioral competences (BC) of managers in a manufacturing company who use mobile technologies.

This study was motivated by the actual needs of managers of manufacturing companies who have a strong desire to make new products in order to be more a knowledge-oriented company. A theoretical model was developed and tested; however, it was evident, that the competences of managers can play a critical role only in the explicit knowledge transfer process within a company. 
The research results indicate that the efficiency of a knowledge transfer depend on the organizational and management competencies of managers and also on their technical competencies and the behavioral competences of managers who use mobile technologies. However, the use of mobile technologies influences only on the transfer of explicit knowledge.

So, what kind of technologies should be used by managers with defined competence to improve the efficiency of the tacit knowledge transfer within a company? A conversation is one of the medium to transfer tacit knowledge, so why the use of naturally medium to conversation such as a mobile technology do not influence on the efficiency of this process? So, the results indicate that the use of the mobile technologies are exclusiv only for the transmission of short messages according to policies and procedures adopted in a company. Also, the use of mobile technologies in manufacturing companies, understood in this research as providing workers with a real-time insight into activities, is useful only for the transfer of an explicit knowledge. Therefore, as a practical implication, companies that aim to achieve an improvement in the number of successful projects must adopt not only mobile technologies to knowledge transfer but also all kinds of methods and tools to tacit knowledge transfer such as knowledge maps, face-to-face meetings, coffee breaks and web blogs. So, it would be useful to provide such research in this context.

\section{Conclusions}

The results of this study demonstrate the clear and measurable existence of a positive effect of the use of mobile technologies by managers, according to their competences, on the efficiency of explicit knowledge transfer in a manufacturing company. This effect was found in data based on research results from 119 Polish manufacturing companies.

By proposing the EEKT model, which addresses the influence of the use of mobile technologies by managers on knowledge transfer, this study contributes potential theoretical understanding to knowledge transfer support applications. The observations enumerated in this paper could then serve as guidelines for an improvement of knowledge transfer processes in a manufacturing company. Future work includes how defined characteristics of managers in a manufacturing company can lead to more effective knowledge transfer processes, as well as an improvement in the number of successful projects in a company.

\section{References}

[1] Abbott D., Brown S., Wilson G. - Development management as reflective practice [in] Journal of International Development, Vol. 19, No. 2, 2007, pp. 187-203.

[2] Alam M., Gale A., Brown M., Khan A.I. - The Importance of Human Skills in Project Management Professional Development [in] International Journal of Managing Projects in Business, Vol. 3, No. 3, 2010, pp. 495-516.

[3] Albino V., Garavelli A.C., Schiuma G. Knowledge transfer and inter-firm relationships in industrial districts: the role of the leader firm [in] Technovation, Vol. 19, 1999, pp. 53-63.

[4] Albino V., Schiuma G., Sivo G. - Firm networks for building maintenance and urban renovation: The technological and organisational evolution [in] European Journal of Purchasing \& Supply Management, Vol. 4, 1998, pp. 21-29.

[5] Chituc C.M., Americo A., Cesar T. - A framework proposal for seamless interoperability in a collaborative networked environment [in] Computers in Industry, Vol. 60, No. 5, 2009.

[6] Cotora L. - Managing and Measuring the Intangibles to Tangibles Value Flows and Conversion Process: Romanian Space Agency case study [in] Measuring Business Excellence, Vol.11, No. 1, 2007, pp. 53-60.

[7] Crawford L. - Senior management perceptions of project management competence [in] International Journal of Project Management, Vol. 23, 2005, pp. 7-16.

[8] Dillman D.A. - Mail and Internet Surveys: The Tailored Design Method. John Wiley \& Sons. Inc., New York 2000.

[9] Hausman A., Johnston W.J. - The impact of coercive and non-coercive forms of influence on trust, commitment and compliance in supply chains [in] Industrial Marketing Management, Vol. 39, No. 3, 2010, pp. 519-526. 
[10] Joshi K.D., Sarker S. - Knowledge transfer within information systems development teams: examining the role of knowledge source attributes [in] Decision Support Systems, Vol. 43, No. 2, 2007, pp. 322-335.

[11] Kim K.K., Umanath N.S., Kim J.Y., Ahrens F., Kim B. - Knowledge complementarity and knowledge exchange in supply channel relationships [in] International Journal of Information Management, Vol. 32, No. 1, 2012, pp. 35-49.

[12] Ko D., Kirsch L., King W. - Antecedents of knowledge transfer from consultations to clients in enterprise system implementation [in] MIS Quarterly, Vol. 29, No. 1, 2005, pp. 59-86.

[13] Lev M. - WEB 2.0 implications on knowledge management [in] Journal of Knowledge Management, Vol. 13, No. 1, 2009, pp. 120-134.

[14] Li X., Roberts J., Yan Y., Tan H. - Knowledge sharing in China-UK higher education alliances [in] International Business Review, Vol. 23, No. 2, 2014, pp. 343-355.

[15] Marra M., Emrouznejad A., Hoc W., Edwards J.S. - The value of indirect ties in citation networks: SNA analysis with OWA operator weights [in] Information Sciences, Vol. 314, 2015, pp. 135-151.

[16] Maruta R. - The creation and management of organizational knowledge [in] KnowledgeBased Systems, Vol. 67, 2014, pp. 26-34.

[17] Nonaka I., Kodama M., Hirose A., Kohlbacher F. - Dynamic fractal organizations for promoting knowledge-based transformation - A new paradigm for organizational theory [in] European Management Journal, Vol. 32, No. 1, 2014, pp. 137-146.

[18] Nonaka I., von Krogh G. - Tacit knowledge and knowledge conversion: Controversy and ad- vancement in organizational knowledge creation theory [in] Organization Science, Vol. 20, No. 3, 2009, pp. 635-652.

[19] Park Ch., Vertinsky I., Becerra M. - Transfers of tacit vs. explicit knowledge and performance in international joint ventures: The role of age [in] International Business Review, Vol. 24, No. 1, 2015, pp. 89-101.

[20] Patalas-Maliszewska J. - Knowledge Worker Management: Value Assessment, Methods, and Application Tools, Springer, Heidelberg Germany, 2013.

[21] Patalas-Maliszewska J., Krebs I. - A model of employee selection for SME based on innovation transfer [in] Proceedings of International Conference on Business Information Systems (Abramowicz W, Tolksdorf R, Węcel K, Eds), 2010, pp. 57-66, Springer Lecture Notes in Business Information Systems 57, Berlin.

[22] Polanyi M. - The tacit dimension, Routledge \& Kegan Paul, London 1966.

[23] Santoro M.D., Saparito P.A. - Self-interest assumption and relational trust in universityindustry knowledge transfer [in] IEEE Transactions on Engineering Management, Vol. 53, No. 3, 2006, pp. 335-347.

[24] Schiuma G. - Managerial foundations of knowledge assets dynamics [in] Knowledge Management Research and Practice, Vol. 7, No. 4, 2009, pp. 290-299.

[25] Williams C. - Transfer in context: Replication and adaptation in knowledge transfer relationships [in] Strategic Management Journal, Vol. 28, 2007, pp. 867-889. 